\title{
Fusobacteria: new taxonomy and related diseases
}

\author{
K. W. BENNETT and A. ELEY*
}

Department of Bacteriology, Royal Hallamshire Hospital, Sheffield S10 2JF and "Department of Experimental and Clinical Microbiology, University of Sheffield Medical School, Sheffield S10 2RX

\begin{abstract}
Summary. Fusobacteria are anaerobic gram-negative bacilli. Since the first reports in the late nineteenth century, various names have been applied to these organisms, sometimes with the same name being applied to different species. More recently, not only have there been changes to the nomenclature, but also attempts to differentiate between species which are believed to be either pathogenic or commensal or both. Because of their asaccharolytic nature, and a general paucity of positive results in routine biochemical tests, laboratory identification of the fusobacteria has been difficult. However, the application of novel molecular biological techniques to taxonomy has established a number of new species, together with the subspeciation of Fusobacterium necrophorum and F. nucleatum, and provided new methods for identification. The involvement of fusobacteria in a wide spectrum of human infections causing tissue necrosis and septicaemia has long been recognised, and, more recently, their importance in intra-amniotic infections, premature labour and tropical ulcers has been reported.
\end{abstract}

\section{Introduction}

Fusobacteria are obligately anaerobic non-sporeforming gram-negative bacilli, forming part of the family Bacteroidaceae, which, until recently, was composed of the genera Bacteroides (now redefined as Bacteroides, Prevotella and Porphyromonas), Fusobacterium and Leptotrichia. As the genus Bacteroides has now been redefined, we have used the name "bacteroides" to indicate those members of the family Bacteroidaceae other than fusobacteria and leptotrichia. The genus Fusobacterium (from the latin fusus - a spindle) was proposed by Knorr ${ }^{1}$ in 1923 for pointed, non-sporing gram-negative bacilli found in the mouth. Fusobacteria are differentiated from the bacteroides by their production of major amounts of $n$ butyric acid alone; iso-butyric and iso-valeric acids are not produced. The bacteroides vary in the fatty acids produced, but none produces $n$-butyric acid alone; leptotrichia produce lactic acid alone. These acids can be detected by gas liquid chromatography (GLC).

The DNA $\mathrm{G}+\mathrm{C}$ content of fusobacteria is in the range $26-34 \mathrm{~mol} \%$, except for $F$. prausnitzii $(52-57 \%$ ) which should probably be deleted from the genus. The $\mathrm{G}+\mathrm{C}$ content of Leptotrichia is $25 \mathrm{~mol} \%$, and of the bacteroides 40-52 mol\% (except B. ureolyticus, $28-32 \mathrm{~mol} \%$, which is misplaced and should probably be included in the genus Campylobacter).
Attempts to identify and differentiate fusiform anaerobes on the basis of the relevant published schemes are met with many discrepancies. Confusion arises from the application of the same name by different workers to different organisms, and this is particularly so with the species now known as $F$. nucleatum and L. buccalis. For example, in the 1975 edition of Topley and Wilson's Principles of Bacteriology, Virology and Immunity, ${ }^{2}$ it is reported that $F$. fusiforme was first described by Vincent ${ }^{3}$ in 1898, and that a similar and possibly identical organism was observed by Veillon and Zuber in $1898^{4}$ and named Bacillus fusiformis. The organism is described as being gram-negative but may contain gram-positive granules, a property exhibited by L. buccalis. Smith, ${ }^{5}$ in 1933 , used the name $B$. fusiformis to describe the organisms isolated from tropical ulcers. His description and photomicrographs bear a striking similarity to $F$. ulcerans ${ }^{6}$ (personal observations), except that Smith reported the colonies to be odour free. Werner, ${ }^{7}$ in 1971, used the name $F$. fusiforme for organisms that were clearly fusobacteria (from biochemical tests), and claimed that the $B$. fusiformis first isolated by Veillon and Zuber in 1898 can be identified as a member of the genus Fusobacterium on account of its morphology and fetid odour. This latter identification was accepted in the eighth edition of Bergey's Manual of Determinative Bacteriology in $1974 .{ }^{8}$ The organism now recognised as L. buccalis has at times been reported as a gram-positive organism. Analysis of the cell-wall 
Table I. Changes in nomenclature of F. nucleatum and L. buccalis since 1879

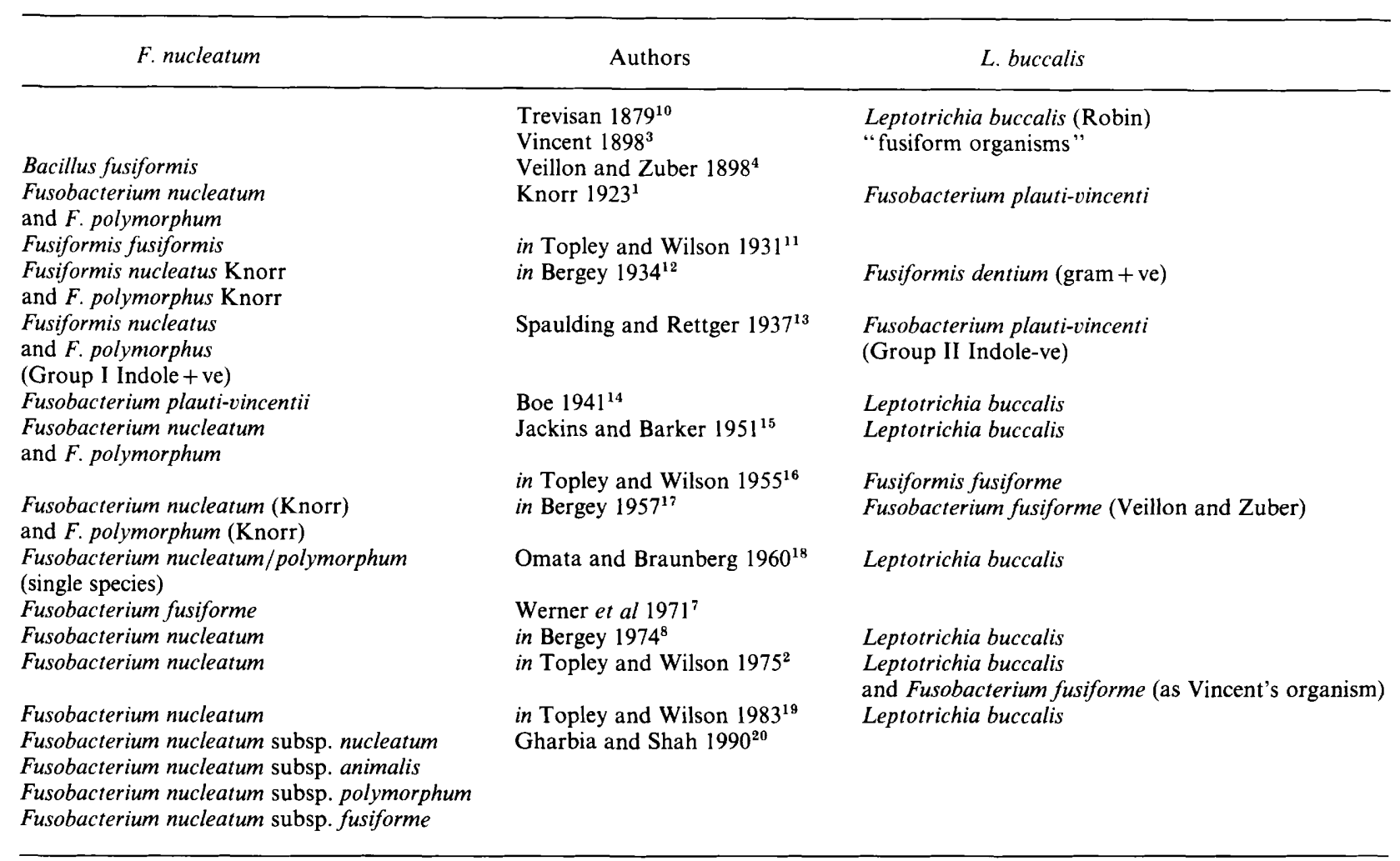

structure has shown it to be gram-negative, ${ }^{9}$ but the organism may exhibit gram-positive granules in the protoplasm, especially in young cultures.

The difficulties experienced with these two species, i.e., F. nucleatum and L. buccalis, are shown in table I, in which an attempt has been made to list the probable identities of the organisms whose names have varied considerably since 1879 .

$F$. necrophorum also has had various names during its history. Finegold ${ }^{21}$ lists 53 synonyms and probable synonyms of this organism. The task of following the multiplicity of names through its history is facilitated by the nature of the diseases caused by this organism, which has been recognised as an animal pathogen since the late $1800 \mathrm{~s}$. The first published description was by Loeffler, who, in $1884,,^{22}$ discussed the importance of the organism in diphtheria of humans, calves and doves. Bang (1881, reported by Madin $^{23}$ ) isolated a fusiform bacillus from liver abscesses in cattle. Mohler and Washburn $(1905)^{24}$ thought that foot rot in cattle was caused by this "necrotic bacillus", and it remains an important pathogen of animals to this day.

$F$. necrophorum is also important in human infections, where it is responsible for the serious condition known as "necrobacillosis"- a necrotic tonsillitis with a grey pseudomembrane, septicaemia and abscess formation, particularly in otherwise healthy young people. This condition, originally described by Lemierre in $1936,{ }^{25}$ seems to have been reported rarely until fairly recently, ${ }^{26,27}$ and this is most probably due to the condition or organism not being recognised.
Other Fusobacterium species have also had synonyms: genus names have included Actinomyces, Proactinomyces, Bacteroides, Bacillus, Pseudobacterium, Sphaerophorus, Ristella, Fusocillus and Zuberella. Fortunately, the species names have remained fairly constant, the exceptions being $F$. mortiferum, for which the species name has been reported as necroticus and rediculosum, and $F$. russii, reported as influenzaeformis.

\section{Newer taxonomy}

Since 1984, when there were 10 Fusobacterium species listed in Bergey's Manual of Systematic Bacteriology, ${ }^{28}$ a number of additions have been made. Six new species have been described ${ }^{29}$, as well as the subspeciation of $F$. nucleatum and $F$. necrophorum (table II). ${ }^{30}$

Of the original group, $F$. prausnitzii is very different from the others and has a DNA G $+\mathrm{C}$ composition of $52-57 \mathrm{~mol} \%$; therefore, this species should be deleted from the genus Fusobacterium. The taxonomic position of $F$. perfoetans is also in doubt as the original strain has been lost, and its proposed neotype strain replacement is very different biochemically from other fusobacteria examined.

Among the newer species, $F$. periodonticum, $F$. alocis and $F$. sulci were all derived from patients with gingivitis and periodontitis; $F$. periodonticum is similar to $F$. nucleatum, whereas $F$. alocis and $F$. sulci are both phenotypically similar to $F$. russii. $F$. simiae was isolated from the oral cavity of a macaque, and $F$. 
Table II. Current species (including subspecies) of Fusobacterium

\begin{tabular}{|c|c|}
\hline 1984 & $\begin{array}{l}\text { Post- } 1984^{20,29,30} \\
\text { (in addition to those listed in 1984) }\end{array}$ \\
\hline $\begin{array}{l}\text { F. necrogenes } \\
F . \text { gonidiaformans } \\
F . \text { varium } \\
\text { F. mortiferum } \\
\text { F. russii } \\
\text { F. naviforme } \\
\text { F. perfoetans } \\
\text { F. prausnitzii } \\
\text { F. necrophorum } \\
\text { F. nucleatum }\end{array}$ & $\begin{array}{l}\text { F. pseudonecrophorum } \\
F . \text { necrophorum subsp. necrophorum } \\
F . \text { necrophorum subsp. funduliforme } \\
F . \text { nucleatum subsp. nucleatum } \\
F . \text { nucleatum subsp. animalis } \\
F . \text { nucleatum subsp. polymorphum } \\
F . \text { nucleatum subsp. fusiforme }\end{array}$ \\
\hline
\end{tabular}

pseudonecrophorum is now proposed as a new species rather than its original designation as biovar $\mathrm{C}$ of F. necrophorum. Moreover, biovars A and B of $F$. necrophorum have now been allocated to $F$. necrophorum subsp. necrophorum and $F$. necrophorum subsp. funduliforme, respectively. $F$. ulcerans was isolated from tropical ulcers and from mud samples taken from areas where patients with tropical ulcers lived.

Nucleic acid (especially DNA) homology studies have been important in helping to show relatedness of certain strains, and were instrumental in dividing $F$. necrophorum into the two subspecies described above ${ }^{30}$ More recently, intergeneric relationships determined by reverse transcriptase sequencing of smallsubunit rRNA have not only confirmed the close relatedness of the four subspecies of $F$. nucleatum (despite their heterogeneity when analysed by SDSPAGE of whole-cell proteins) by showing that they exhibited high levels of sequence homology with each other, but also shown that they were similar to $F$. alocis, $F$. periodonticum and $F$. simiae, all of which colonise oral cavities. ${ }^{31}$

\section{Laboratory diagnosis}

Fusobacteria are difficult to recognise in the clinical laboratory. Although the nomenclature and classification of fusobacteria has been clarified $^{32}$ there are few stable and specific tests for the routine laboratory differentiation of the species. ${ }^{33}$ Only $F$. nucleatum is consistently fusiform (spindle-shaped) by Gram's stain, and many isolates are not readily distinguishable from bacteroides strains, especially from some of the asaccharolytic species. GLC analysis of volatile and nonvolatile fatty acid end products is the basis for the classification of the three groups of the Bacteroidaceae: Fusobacterium spp. produce major amounts of $n$-butyric acid, without iso-butyric or iso-valeric acids, but this does not help to identify species within the genus, as all species give the same results. GLC may be carried out directly on, e.g., blood culture broths, pus and other exudates, giving an indication of the presence of a Fusobacterium sp. without the need to wait for the results of culture. Detection of propionate produced from lactate is diagnostic of $F$. necrophorum, but the detection of propionate produced from threonine is less helpful, as most species of Fusobacterium can do this. The differentiation between Fusobacterium spp. and $L$. buccalis can be made readily by using GLC analysis, as $L$. buccalis produces lactic acid.

Since fusobacteria are often present in mixed cultures with other obligate anaerobes and with facultative species, the use of a selective medium is often necessary for their isolation. Media incorporating erythromycin, vancomycin and josamycin at 100, 5 and $3 \mathrm{mg} / \mathrm{L}$, respectively, have been used, ${ }^{34}$ and more recently josamycin, vancomycin and norfloxacin at 3 , 4 and $1 \mathrm{mg} / \mathrm{L}$, respectively, have been reported to inhibit most other organisms. ${ }^{35}$ The addition of egg yolk to such media can enable colonies of $F$. necrophorum to be recognised easily due to their production of a lipase.

Colonial morphology is not very helpful for inexperienced observers. $F$. nucleatum appears in three colonial types: a speckled, iridescent colony, a breadcrumb-type colony and a smooth colony. The speckled colony is readily recognised, but can be mistaken for Capnocytophaga spp., which are also fusiform when Gram's stain is used. L. buccalis has a feathery colony, which is readily recognised. $F$. nucleatum is the only fusobacterium which consistently appears as fusiformshaped bacilli; these should not be confused with $L$. buccalis which is also fusiform, but may contain gram-positive granules. Films of $F$. necrophorum may show sphaeroplast formation, and $F$. mortiferum and $F$. ulcerans show bizarre, pleomorphic bacilli, with large coccoid forms.

Identification of an anaerobic gram-negative bacillus begins with the differentiation of a Fusobacterium or Leptotrichia isolate from other non-spore-forming gram-negative anaerobic bacilli. Whilst GLC analysis of short chain-fatty acid products of metabolism is recognised as the "gold standard" here, this piece of apparatus is not always available. The phosphomycin sensitivity test is a very simple and effective test. Amongst the anaerobic gram-negative bacilli, all strains of Fusobacterium and Leptotrichia are sensitive to concentrations of $100 \mathrm{mg} / \mathrm{L}$ whereas species of most of the other genera are resistant to $500 \mathrm{mg} / \mathrm{L} ;{ }^{36}$ the exceptions are $B$. capillosis, B. furcosis, B. praeacutus and $B$. ureolyticus. ${ }^{33}$ As $B$. ureolyticus is urease positive, and the other species are rarely isolated from human clinical specimens, this single test enables the presumptive identification of an isolate as a fusobacterium or leptotrichia with some confidence. The phosphomycin (Sigma) may be incorporated into agar media at a concentration of $100-300 \mathrm{mg} / \mathrm{L}$ for testing multiple isolates, or a disk containing $100-300 \mu \mathrm{g}$ may be used. 
Table III. Characterisation of fusobacteria

\begin{tabular}{|c|c|c|c|c|c|c|c|c|c|}
\hline Species & $\begin{array}{c}\text { DNA } \\
\mathrm{G}+\mathrm{C} \\
\mathrm{mol} \%\end{array}$ & Indole & $\begin{array}{c}\text { Propionate } \\
\text { from threonine }\end{array}$ & $\begin{array}{l}\text { Propionate } \\
\text { from lactate }\end{array}$ & $\begin{array}{l}\text { Gas from } \\
\text { glucose }\end{array}$ & $\begin{array}{c}\text { Bile } \\
\text { resistance }\end{array}$ & $\begin{array}{c}\text { Aesculin } \\
\text { hydrolysis }\end{array}$ & $\begin{array}{c}\text { Phosphatase } \\
\text { activity }\end{array}$ & $\begin{array}{l}\text { ONPG } \\
\text { activity }\end{array}$ \\
\hline F. necrophorum & $31-34$ & + & + & + & + & $-(+)$ & - & + & - \\
\hline F. nucleatum & $27-28$ & + & + & - & $-(+)$ & $-(+)$ & - & - & - \\
\hline$F$. naviforme & $32-33^{*}$ & + & - & $\longrightarrow$ & - & - & - & - & - \\
\hline F. varium $\dagger$ & 29 & + & + & - & + & + & - & - & - \\
\hline F. gonidiaformans & $31-33$ & + & + & - & + & - & - & - & - \\
\hline F. necrogenes & 28 & - & + & - & + & $+(-)$ & + & + & - \\
\hline F. mortiferum & $26-28$ & - & + & - & + & + & + & - & + \\
\hline F.russii & 31 & - & - & - & $-(+)$ & - & - & + & - \\
\hline F. ulcerans & 29 & - & + & - & + & $+(-)$ & - & - & - \\
\hline F. varium $\dagger$ & 29 & - & + & - & + & + & - & - & - \\
\hline L. buccalis & 25 & - & - & - & - & - & + & + & - \\
\hline
\end{tabular}

*The type strain ATCC 25832 is atypical, having a G + C content of $49 \mathrm{~mol} \%$.

$\dagger F$. varium gives a variable indole reaction.

Identification of species within the genera Fusobacterium and Leptotrichia may be made with the tests shown in table III $^{32,33}$ (and Bennett, unpublished data). The tests may be made more convenient by the use of impregnated disks rather than incorporating the reagents in an agar medium. Disks may be prepared with solutions made in distilled water and sterilised by membrane filtration. The solutions are added to the disks in $20-\mu \mathrm{l}$ amounts and the disks are then freezedried and stored at $2-8^{\circ} \mathrm{C}$ :

Bile disks, ox-gall $1 \mathrm{~g} / 2 \mathrm{ml}$; phosphatase disks, 4nitrophenyl disodium orthophosphate $1 \mathrm{~g} / 10 \mathrm{ml}$; ONPG disks, $o$-nitrophenyl- $\beta$-galactopyranosidase $0.25 \mathrm{~g} / 10 \mathrm{ml}$.

The disks should be used on Columbia agar base without blood, although the growth of the organisms may not be as good as on Fastidious Anaerobe Agar (FAA). Plates should be examined after $48 \mathrm{~h}$ as the colours produced by phosphatase and ONPG reactions may diffuse with prolonged incubation.

Several kits are now available commercially for use in the identification of anaerobes; they are based upon the detection of pre-formed enzymes to give a result in $4 \mathrm{~h}$. The species of Fusobacterium listed in these kits are generally $F$. necrophorum, $F$. nucleatum, $F$. mortiferum, $F$. necrogenes and $F$. varium, as these are thought to be the species most commonly isolated from human clinical specimens. There are no provisions for identifying other species.

In two studies with the API 32ATB system (API bioMérieux (UK) Ltd, Basingstoke), a total of 32 strains of fusobacteria was tested, 17 of which were $F$. nucleatum. Only $F$. mortiferum (three of four strains tested) was correctly identified without the need for further tests. Of this group of 32 strains, four were incorrectly identified. $\mathrm{Nash}^{37}$ examined strains of nine species of Fusobacterium with the API 32ATB system and found that $F$. nucleatum, $F$. necrophorum and $F$. gonidiaformans generally could not be separated by the test reactions alone, and that no constant patterns of reactions for the strains representing $F$. mortiferum and $F$. necrophorum could be discerned. In fact, culture on an egg-yolk agar for lipase production, glucose agar for gas production, and a test for indole production will readily distinguish between these organisms. $F$. necrophorum alone usually produces lipase, and also produces large amounts of gas from glucose, as does $F$.gonidiaformans. $F$. nucleatum gives negative results in both tests. $F$. mortiferum produces gas but not indole. In two studies with Rapid ANA (Innovative Diagnostics Systems Inc., Atlanta, GA, USA) and AN-IDENT (Analytab Products, Plainview, NY, USA), a total of 41 strains of fusobacteria was examined. Both kits gave similar results; 34 strains were identified correctly to species level and seven to genus level; none was incorrectly identified. The paucity of positive reactions found in conventional biochemical tests with the fusobacteria is reflected in the poor performance of these kits, but they may be of help in confirming a suspected identity.

More recently, a whole genomic DNA probe has been used successfully to detect $F$. nucleatum directly in samples of subgingival plaque. ${ }^{38}$ The use of a synthetic oligonucleotide DNA probe has allowed differentiation between unrelated strains of this organism, ${ }^{39}$ although results have not been reported on their direct application to clinical material.

\section{Characterisation by novel methods}

Species. Of the modern methods of whole-cell analysis, polyacrylamide gel electrophoresis (PAGE) of soluble proteins (without sodium dodecyl sulphate), has proved quite useful in the separation of certain species of Fusobacterium, e.g., F. ulcerans, F. alocis and $F$. sulci, from others. However, for most species, the electrophoretic patterns derived are too complex and inconsistent within a species. ${ }^{40}$ Pyrolysis mass spectrometry of whole cells of different species of Fusobacterium was reasonably successful in differentiating between some strains within a species. However, at best, other strains could be assigned only to clusters of the dendrogram which represents the relationship between strains, based on the mass spec- 
trometry data. ${ }^{41}$ Of perhaps greater potential is identification based upon the electrophoretic migration of glutamate dehydrogenase (GDH) and 2-oxoglutarate reductase (OGR) which provides a useful and rapid method for identifying most species. ${ }^{42}$ The most powerful method so far used to characterise 11 species of Fusobacterium has been comparative analysis of small-subunit rRNA sequences. ${ }^{31}$ Although all the species examined showed relatively high levels of sequence similarity, characteristic differences were observed that enabled separation of species, together with a display of considerable intergeneric heterogeneity.

Subspecies. Four subspecies of $F$. nucleatum are now recognised ${ }^{20}$ (table II). Several studies, including soluble protein profiles, ${ }^{40}$ pyrolysis mass spectrometry $^{41}$ and electrophoretic migration of GDH and OGR, ${ }^{42}$ previously showed that $F$. nucleatum represented a heterogeneous group of organisms. These findings have been confirmed by rRNA gene restriction patterns or ribotyping, ${ }^{43}$ and by comparative analysis of small-subunit rRNA sequences. ${ }^{31}$ In ribotyping, chromosomal DNA is digested with either EcoRI or TaqI restriction endonuclease, and the resulting fragments are hybridised with a ${ }^{32} \mathrm{P}-16 \mathrm{~S}$ rRNA gene probe from Escherichia coli. Although only three subspecies were tested by ribotyping, all were easily separated. Surprisingly, despite the recognition of two subspecies of $F$. necrophorum, to date similar methods of investigations have not been reported.

\section{Spectrum of human infections}

Anaerobic bacteria are present among the normal bacterial population of the human body, particularly on the mucosal surfaces, in proximity to which most anaerobic infections arise. The major sites with a rich anaerobic normal flora are the mouth and upper respiratory tract, the gastrointestinal (GI) tract, and the female genital tract. Fusobacteria are found in large numbers in the mouth, but are not a major part of the faecal or vaginal flora. They have been isolated frequently from a wide variety of clinically significantly anaerobic infections that include oral and dental infections, brain abscess, empyema, hepatic and intraabdominal abscess, septicaemia and endocarditis, and soft tissue infections; they are often found in combination with other anaerobes and aerobes in polymicrobial infections. Table IV lists the sites and infections from which fusobacteria have been isolated.

Many extracellular products that may contribute to pathogenicity have been identified. Fusobacterial lipopolysaccharide endotoxin, like that of facultative gram-negative bacteria, but unlike Bacteroides spp. and other gram-negative anaerobic genera, contains readily detectable keto deoxyoctanoate and appears to endow virulence properties, as do neutrophil-cytotoxic substances and DNAase; $F$. necrophorum also produces a haemolysin and a leukocidin. $\beta$-Lactamase produced by $F$. nucleatum protects the organism from penicillin and other $\beta$-lactam antibiotics frequently used for the treatment of anaerobic infections.

Host factors associated with fusobacterial infection include disruption of the normal cutaneous and mucocutaneous barriers, tissue injury (surgical or accidental trauma), and impaired blood supply leading to hypoxia. Devitalised tissue provides the necessary low redox potential and oxygen-free environment for the growth of these organisms. The production of proteolytic enzymes by fusobacteria may allow invasion of regional veins, even without tissue necrosis.

Infections of the mouth, head and neck, and chest. The concentration of anaerobes in the normal flora of the oral cavity is 10 -fold higher than that of aerobes. Fusobacteria are usually present in large numbers, and account for $4 \%$ of anaerobic organisms cultivable from plaque, ${ }^{21}$ but a much larger proportion of those seen by microscopy. Infections of the oral cavity often extend to the head and neck, respiratory tract, and, via the blood stream, to cause metastatic abscess formation.

In human necrobacillosis, caused by $F$. necrophorum, necrotising tonsillitis gives rise to septicaemia, leading to metastatic spread. Serious complications including, for example, lung abscess, septicaemia and brain abscess, may occur with anaerobic tonsillitis. Although most of these infections are endogenous in origin, infection may also be by exogenous acquisition of a virulent strain.

Because of their association with the upper respiratory tract flora, fusobacteria are frequently isolated from chest infections, including aspiration pneumonia, lung abscess and empyema. Aspiration is the usual mechanism leading to anaerobic lung abscess, though this may also be caused by metastatic bacteraemic spread from oral or pharyngeal infection.

Fusobacteria have been associated with $46 \%$ of anaerobic infections of the head and neck, and with $28.5 \%$ of cases of complicated sinusitis. ${ }^{44}$ Space infections of the head and neck generally arise from extension of bacterial infection of the upper airways to involve the potential spaces formed by the fascial planes. Because of antibiotic therapy of respiratory tract infections, these infections are not now seen so commonly, but are probably under-diagnosed. Infections have been reported from all sinuses and mucosal surfaces and tissues of the head and neck, including oral, cerebral, eye, ear and mastoid infections, meningitis and cavernous sinus thrombosis.

Otitis media or mastoiditis, usually chronic, is the most common underlying source of anaerobic infections of the central nervous system (CNS), particularly brain abscess and meningitis. It is generally accepted that anaerobic bacteria are not the most common causes of acute otitis media or mastoiditis, but severe, and sometimes fatal cases involving $F$. necrophorum have been reported. As anaerobes are so commonly involved in chronic infections, it is possible that they may be implicated in acute processes also. 
Table IV. Spectrum of fusobacterial infections

\begin{tabular}{|c|c|c|}
\hline Site & Type of in & tion \\
\hline \multirow{11}{*}{$\begin{array}{l}\text { Blood } \\
\text { Head and neck }\end{array}$} & Septicaemia & Post-anginal septicaemia \\
\hline & $\begin{array}{l}\text { Otitis media (acute and } \\
\text { chronic) }\end{array}$ & \\
\hline & Sinusitis & Vincent's angina \\
\hline & Mastoiditis & Thyroiditis \\
\hline & Parotitis & Peritonsillar abscess \\
\hline & Recurrent tonsillitis & \\
\hline & Cervical lymphadenopathy & \\
\hline & Retropharyngeal abscess & \\
\hline & Dental infections & Gingivostomatitis \\
\hline & Eye infections & \\
\hline & Orbital cellulitis & Maxillary sinusitis \\
\hline \multirow[t]{2}{*}{ Chest } & Empyema & Lung abscess \\
\hline & Aspiration pneumonia & \\
\hline \multirow[t]{2}{*}{ Central nervous system } & Meningitis & Cerebral abscess \\
\hline & Cerebritis & \\
\hline \multirow[t]{2}{*}{ Cardiovascular system } & Thrombophlebitis & Endocarditis \\
\hline & Pericarditis & \\
\hline \multirow[t]{3}{*}{ Abdomen } & Liver abscess & Intra-abdominal abscess \\
\hline & Appendicitis & Peritonitis \\
\hline & $\begin{array}{l}\text { Perirectal and perineal } \\
\text { infections }\end{array}$ & \\
\hline \multirow[t]{3}{*}{ Genital tract } & $\begin{array}{l}\text { Amnionitis (and intra-amniotic } \\
\text { infections) }\end{array}$ & \\
\hline & Prostatic abscess & \\
\hline & Female genital tract infections & \\
\hline Bone and joint & Osteomyelitis & Arthritis \\
\hline \multirow[t]{2}{*}{ Miscellaneous } & $\begin{array}{l}\text { Soft tissue infections } \\
\text { (including "noma" and bite } \\
\text { wounds) }\end{array}$ & \\
\hline & Tropical ulcers & \\
\hline
\end{tabular}

Infections of the urethra and female genital tract. Most bacteria responsible for gynaecological, obstetric and severe neonatal infections are derived from the indigenous genital tract flora. Together with the mouth and GI tract, the female genital tract is a major site of anaerobic normal flora, with anaerobes outnumbering aerobes 10-100-fold, and fusobacteria are usually found to be present. Fusobacteria from the vagina reach the normally sterile uterus, fallopian tubes and pelvis as a result of surgery, trauma or unskilled interference, or physiological dysfunction of these structures. F. necrophorum is the species most commonly involved; it has been isolated from infections resulting from spontaneous and induced abortion, caesarian section and from pelvic peritonitis, with bacteraemia being a common complication of these infections. Fusobacteria play a role in the pathogenesis of premature labour ${ }^{45,46}$ it has been suggested that amniotic fluid cultures for fusobacteria should be done on all women presenting with premature labour and intact membranes who do not respond to tocolytic drugs. ${ }^{46}$

Anaerobes are found as normal flora in the male urethra, and fusobacteria have been associated with some infections--periurethral cellulitis and abscess, and cystitis-although these infections are rare. Fusobacteria have also been isolated from metastatic abscesses of the kidney.

Septicaemia and meningitis. Fusobacteria account for about $1 \%$ of all bacteraemias, and about $11 \%$ of anaerobic bacteraemias. ${ }^{44}$ They are usually associated with primary oropharyngeal infection complicated by neck vein thrombosis with metastatic spread. Of particular importance is post-anginal septicaemia (necrobacillosis), which was often a lethal condition in the pre-antibiotic era. Lemierre, ${ }^{25}$ in 1936, described the classical symptoms which are still relevant today. Because of antibiotic therapy, this condition is now seen less frequently, and is, therefore, not readily recognised. The commonest presentation is in a previously healthy young adult, after a sore throat which is followed by rigors, systemic toxicity and metastatic abscesses, usually in the lung but also in the bone, CNS and other sites. In the absence of a sore throat, otitis, mastoiditis, sinusitis or dental infections are usually found.

Fusobacteria are the most likely cause of bacteraemia when the oropharynx is the portal of entry. Reports of osteomyelitis and pulmonary infection following tooth extraction show that clinically insignificant bacteraemia may lead to severe consequences. Fusobacterial sepsis has followed human bites, diarrhoea in infants, and prostatic abscess.

Although the incidence of anaerobes in pericarditis is apparently very low, cases involving fusobacteria (usually $F$. nucleatum or $F$. necrophorum) have been reported. Although not common, endocarditis due to anaerobes is not rare, with $F$. necrophorum being the species most frequently involved. ${ }^{21}$ Usually, reported cases have also involved infections of the oral cavity with the same organisms.

Anaerobic bacteria are not uncommon causes of 
Table V. Sites of infection with Fusobacterium species

\begin{tabular}{|c|c|c|c|c|c|c|c|c|}
\hline Species & Blood & $\begin{array}{c}\text { Head } \\
\text { and } \\
\text { neck }\end{array}$ & $\begin{array}{c}\text { Pleuropulmonary } \\
\text { including oral and dental }\end{array}$ & CNS & Abdomen & GU tract & $\begin{array}{c}\text { Bone } \\
\text { and } \\
\text { joint }\end{array}$ & $\begin{array}{l}\text { Soft } \\
\text { tissue }\end{array}$ \\
\hline$F$. necrophorum & + & + & $+(N F)$ & + & $+(\mathrm{NF})$ & $+(\mathrm{NF})$ & + & + \\
\hline F. nucleatum & + & + & $+(\mathrm{NF})$ & + & $+(\mathrm{NF})$ & $+(\mathrm{NF})$ & + & + \\
\hline F. gonidiaformans & + & + & $+(\mathrm{NF})$ & + & $+(\mathrm{NF})$ & $+(\mathrm{NF})$ & + & + \\
\hline$F$. mortiferum & + & + & $+(\mathrm{NF})$ & + & $+(\mathrm{NF})$ & $+(\mathrm{NF})$ & + & + \\
\hline$F$. naviforme & - & + & $+(\mathrm{NF})$ & + & $-(\mathrm{NF})$ & - & + & + \\
\hline$F$. necrogenes & + & + & - & - & $+(\mathrm{NF})$ & - & - & - \\
\hline F. russii & + & + & $+(\mathrm{NF})$ & + & $-(N F)$ & $+(\mathrm{NF})$ & + & + (animal bites) \\
\hline F. varium & - & + & + & - & $+(\mathrm{NF})$ & $-(\mathrm{NF})$ & + & + (eye infections) \\
\hline
\end{tabular}

NF, normal flora at these sites.

meningitis. Anaerobic meningitis is often part of a more extensive intracranial infection, e.g., brain abscess, extradural or subdural abscess, or cavernous sinus thrombosis. Otitis media or mastoiditis are the most common sources of fusobacterial infection, with either $F$. nucleatum or $F$. necrophorum involved. Subdural and extradural empyemas have been reported with these organisms, in association with brain abscess, mastoiditis, sinusitis and otitis.

Fusobacteria are common causes of brain abscess related to ear or mastoid abscess, and lung or pleural space disease. The underlying condition is usually chronic, with lung abscess, bronchiectasis, empyema and necrotising pneumonia the most frequent types of lung infection involved. The most common causes, in order of importance, are ear infections, lung infections and sinusitis. Brain abscess secondary to ear infection and sinusitis is through direct extension of the infection to the brain. Brain abscess secondary to lung disease is blood-borne. Studies have suggested that blood-borne organisms first invade the parenchyma of the brain, causing cerebritis, vasculitis or both. ${ }^{21}$

Abdominal infections. Fusobacteria are part of the normal flora of the GI tract, where anaerobes outnumber aerobes 1000 -fold. Though infections here are mostly due to Bacteroides spp., fusobacteria have been isolated from a wide range of abdominal infections, including chronic ulcerative colitis, post-operative wound infection, abdominal wall abscess, intraperitoneal abscess, psoas abscess, peritonitis, appendicitis and spleen and liver abscesses, as well as perirectal and perineal infections. The species most commonly reported is $F$. necrophorum.

Bone and joint infections. Osteomyelitis involving the bones of the skull is the commonest site for bone involvement with fusobacteria; the species most commonly isolated is $F$. necrophorum. This species also accounts for the majority of cases of anaerobic purulent arthritis, in which it accounts for $>33 \%$ of the total anaerobes recovered; in most cases the joints became infected in the course of generalised (septicaemic) anaerobic sepsis. $F$. necrophorum is generally isolated from osteomyelitis of the long bones; $F$. mortiferum and $F$. nucleatum are also implicated occasionally.
Soft tissue infections. Among the soft tissue infections involving fusobacteria are two specific fusobacterial conditions-noma and tropical ulcer.

Noma - cancrum oris or gangrenous stomatitis-is a devastating orofacial gangrenous condition involving mucous membranes or mucocutaneous surfaces. It occurs most commonly around the mouth, often following necrotising ulcerative gingivitis, but it may affect the nose, auditory canal, vulva, prepuce or anus. Untreated, the process may lead to almost complete destruction of the face before death. It is thought to be a mixed Porphyromonas asaccharolyticafusobacterium-spirochaetal infection.

Tropical ulcer is a disease found most commonly in the tropics, although it is not confined to these areas. Young children are most commonly affected, and the disease is thought to be a polymicrobial infection with fusobacteria, aerobic organisms and spirochaetes. Fusobacteria have long been recognised in smears from tropical ulcers, and from these sites Smith $^{5}$ isolated an organism which he called Bacillus fusiformis. Many years later, Adriaans ${ }^{6}$ isolated a previously undescribed fusobacterium for which the name F. ulcerans was later proposed.

Fusobacteria, not always identified to species level, have been isolated from many infections of soft tissue, skin and muscle, including animal and human bite wounds. $F$. necrophorum has been isolated from anaerobic cellulitis, and pilonidal and sacral dermoid cysts. Fusobacteria have also been isolated from Fourniere's gangrene, diabetic gangrene of the foot and buttock abscesses.

Although $F$. necrophorum and $F$. nucleatum are the most commonly reported fusobacteria, other species are also involved in infections. Table $\mathrm{V}$ shows the sites from which fusobacteria, including the lesser known species, have been isolated. Soft tissue sites infected by $F$. russii have been animal bites, and $F$. varium has been associated with conjunctivitis and intra-ocular infections.

\section{Antibiotic therapy}

In the past, routine susceptibility testing of fusobacteria was not usually recommended as the organ- 
isms were generally sensitive to many agents and antimicrobial therapy was determined empirically. There was a reasonable level of predictability of antimicrobial susceptibility that served as the basis for selection of appropriate initial therapy. However, the emergence of antibiotic resistance and the introduction of new antibiotics has necessitated testing of strains isolated from serious infections. Overall, perhaps the most widely accepted method for susceptibility testing is the agar dilution break-point method. However, even an agar dilution procedure that has been accepted in the USA by the National Committee for Clinical Laboratory Standards is still not ideal, ${ }^{47}$ because, even with the addition of blood to the recommended culture medium, some strains of fusobacteria do not grow, or grow so poorly that results cannot be considered reliable. Furthermore, there can often be difficulty in determining the end-point of growth, especially with $\beta$-lactam antibiotics, due to a visible haze composed of cell wall-defective variants. ${ }^{48} \mathrm{~A}$ recent report ${ }^{49}$ suggested that Fastidious Anaerobe Agar (Lab M) may be a more suitable medium for susceptibility testing of fusobacteria, with fewer tailing end-points.

Until a few years ago, almost all fusobacteria were susceptible to metronidazole, penicillin $G$, clindamycin, cefoxitin, chloramphenicol, tetracycline and to many newer cephalosporins and penicillins; in contrast, vancomycin and erythromycin showed only limited activity, and aminoglycosides were ineffective. More recently, increasing numbers of strains have been found that are resistant to some of these drugs. Often these strains are members of rarely isolated species such as $F$. varium and $F$. mortiferum that are principally resistant to $\beta$-lactam drugs due to $\beta$-lactamase activity. ${ }^{50}$ The first description of a $\beta$ lactamase in fusobacteria was reported in $1985,{ }^{51}$ and this was shown primarily to be a penicillinase with little activity against cephalosporins. As the isolation of $\beta$-lactamase-producing fusobacteria appears to be increasing, their clinical significance needs to be reassessed. Even with effective antimicrobial drugs, treatment usually requires a combination of surgical drainage or excision of the infected tissue, together with antimicrobial therapy; the latter is of especial importance in patients with weakened host defences.

\section{Conclusion}

Since the first reports of fusobacteria in the late nineteenth century, the variety of species names has led to some confusion within the genera Fusobacterium and Leptotrichia. However, newer methods of investigation have led to a better understanding of the taxonomy, with the description of several new species of fusobacteria. Among the new species described are $F$. ulcerans from tropical ulcers, and several species from the oral cavity. Subspeciation of the important species $F$. necrophorum and $F$. nucleatum has also been possible. It is probable that the taxonomy of the fusobacteria may be further developed in the future.

\section{References}

1. Knorr M. Uber die fusispirillare Symbiose, die Gattung Fusobacterium. Zentralbl Bakteriol Parasitkde Abt Orig $1923 ; 89: 4$.

2. Wilson GS, Miles AA. In: Topley and Wilson's Principles of bacteriology, Virology and immunity, 6th edn. London, Edward Arnold. 1975: 646-658.

3. Vincent $\mathrm{MH}$. Sur une forme particuliere d'angine diptheroide (angine a bacilles fusiformes). Bull Mem Soc Med Hop Paris 1898 (3); 15 : 244.

4. Veillon A, Zuber A. Recherches sur quelques microbes strictement anaerobies et leur role en pathologie. Arch Med Exp Anat Pathol 1898; 10 : 517.

5. Smith EC. Inoculation experiments with Bacillus fusiformis isolates from tropical ulcer with observations on the bacillus. J Hyg 1933; 33: 95-102.

6. Adriaans B, Draser BS. The isolation of fusobacteria from tropical ulcers. Epidemiol Infect 1987; 99: 361-372.

7. Werner H, Neuhaus F, Hussells $H$. A biochemical study of fusiform anaerobes. Med Microbiol Immunol 1971; 157: 10-16.

8. Holdeman LV, Moore WEC. Bacteroidaceae. In: Buchanan RE, Gibbons NE (eds) Bergey's Manual of determinative bacteriology, 8th edn. Baltimore, Williams and Wilkins Co. 1974: $384-426$.

9. Hofstad T, Selvig KA. Ultrastructure of Leptotrichia buccalis. J Gen Microbiol 1969; 56: 23.

10. Trevisan V. Prime Lince d'introduzione allo Studio dei Batterj Italiani. Reale Instituto Lombardo di Scienze e Lettre Ser II $1879 ; 12: 133$.

11. Topley WC, Wilson GS. In: Topley and Wilson's Principles of bacteriology and immunity, 1st edn. London, Edward Arnold. 1931: 1-587.

12. Breed RS, Murray EGD (eds). In: Bergey's Manual of determinative bacteriology 4 th edn. Baltimore, Williams and Wilkins Co. 1934.

13. Spaulding EH, Rettger IF. Fusobacterium genus; biochemical and serological classification. $J$ Bacteriol 1937 ; 34: 535548.

14. Boe J. Fusobacterium. Studies on its bacteriology, serology and pathogenicity. Norske Videnskaps-Akad Oslo I Mat-Naturv Klasse 1941; 9: 1-191.

15. Jackins HC, Barker HA. Fermentative processes of the fusiform bacteria. J Bacteriol 1951; 61 : 101-114.

16. Wilson GS, Miles A. Bacteroidaceae. In: Topley and Wilson's Principles of bacteriology and immunity, 4th edn. London, Edward Arnold. 1955: 565-575.

17. Hoffman H. Fusobacterium (Knorr). In: Breed RS, Murray EGD, Smith NR (eds) Bergey's Manual of determinative bacteriology, 7 th edn. Baltimore, Williams and Wilkins Co. 1957: $436-440$.

18. Omata RR, Braunberg RC. Oral fusobacteria. J Bacteriol 1960; 80: $737-740$.

19. Duerden BI. Bacteroidaceae-Bacteroides, Fusobacterium and Leptotrichia. In: Wilson G, Miles AA, Parker MT (eds) Topley and Wilson's Principles of bacteriology, virology and immunity 7 th edn, vol 2. London, Edward Arnold. 1983: $114-136$.

20. Gharbia S, Shah H. Heterogeneity within Fusobacterium nucleatum. Proposal of four subspecies. Leti Appl Microbiol 1990; 10 : 105-108.

21. Finegold SM. Anaerobic bacteria in human disease. New York, Academic Press, 1977: 13-14, 29, 162, 201-204.

22. Loeffler F. Untersuchungen uber die Bedeutung von Mikroorganismen. Mitt a d Kais Ges II Bd $2 S$ 1884; 489.

23. Madin SH. A bacteriologic study of bovine liver abscesses. Vet Med 1949; 44: 248-251. 
24. Mohler JR, Washburn JJ. Foot rot in sheep: its nature, cause and treatment. U.S. Bureau of Animal Industry Bull 63. Washington, D.C., Gov Printing Office. 1905.

25. Lemierre A. On certain septicaemias due to anaerobic organisms. Lancet 1936; 1: 701-703.

26. Alston JM. Necrobacillosis in Great Britain. BMJ 1955; 2: 1524-1528.

27. Moore-Gillon J, Lee TH, Eykyn SJ, Phillips I. Necrobacillosis: a forgotten disease. $B M J 1984 ; 288$ : 1526-1527.

28. Holdeman LV, Kelley RW, Moore WEC. Bacteroidaceae. In: Krieg NR, Holt JG (eds) Bergey's Manual of systematic bacteriology, 1st edn, vol 1. Baltimore, Williams and Wilkins Co. 1984: 602-662.

29. Hofstad T. Recent changes in the taxonomy of fusobacteria. In: Duerden BI, Brazier JS, Seddon SV, Wade WG (eds) Medical and environmental aspects of anaerobes. Petersfield, Wrightson Biomedical Publishing Ltd. 1992: 199204.

30. Shinto T, Fujisawa T, Mitsouka T. Proposal of two subspecies of Fusobacterium necrophorum (Flugge) Moore and Holdeman: Fusobacterium necrophorum subsp. necrophorum subsp. nov., nom. rev. (ex Flugge 1886), and Fusobacterium necrophorum subsp. funduliforme subsp. nov., nom. rev. (ex Halle 1898). Int J Syst Bacteriol 1991; 41 : 395-397.

31. Lawson PA, Gharbia SE, Shah HN, Clarke DR, Collins MD. Intrageneric relationships of members of the genus Fusobacterium as determined by reverse transcriptase sequencing of small-subunit rRNA. Int $J$ Syst Bacteriol $1991 ; 41$ : 347-354.

32. Holdeman LV, Moore WEC (eds). Anaerobic laboratory manual, 4th edn. Blacksburg, VA, Virginia Polytechnic Institute and State University. 1977 and Supplement 1987.

33. Bennett $\mathrm{KW}$, Duerden BI. Identification of fusobacteria in a routine diagnostic laboratory. $J$ Appl Bacteriol 1985; 59: 171-181.

34. Morgenstein AA, Citron DM, Finegold SM. New medium selective for Fusobacterium species, and differential for Fusobacterium necrophorum. J Clin Microbiol 1981; 13: 666-669.

35. Brazier JS, Citron DM, Goldstein EJC. A selective medium for Fusobacterium spp. J Appl Bacteriol 1991; 71: 343-346.

36. Garcia Rodriguez JA, Prieto Prieto J, Garcia Sanchez JE, Saenz Gonzales MC, Martin Luengo F. Susceptibility to phosphomycin as a differential characteristic for gramnegative anaerobic bacilli. J Appl Bacteriol 1974; 41 : 251-254.

37. Nash R. Fusobacterium and Bacteroides reactions in a new API anaerobe test system. In: Hardie JM, Borriello SP (eds) Anaerobes today. Chichester, John Wiley and Sons. 1988: 254-255.

38. Lippke JA, Peros WJ, Keville MW, Savitt ED, French CK.
DNA probe detection of Eikenella corrodens, Wolinella recta and Fusobacterium nucleatum in subgingival plaque. Oral Microbiol Immunol 1991; 6: 81-87.

39. Bolstad AI, Skang N, Jensen HB. Use of synthetic oligonucleotide DNA probes for the identification of different strains of Fusobacterium nucleatum. J Period Res 1991 ; 26 : 519-526.

40. Calhoon DA, Mayberry WR, Slots J. Cellular fatty acid and soluble protein profiles of oral fusobacteria. $J$ Dent Res $1983 ; 62$ : 1181-1185.

41. Magee JT, Hindmarch JM, Bennett KW, Duerden BI, Aries RE. A pyrolysis-mass spectrometry study of fusobacteria. $J$ Med Microbiol 1989; 28 : 227-236.

42. Gharbia SE, Shah HN. Identification of Fusobacterium species by the electrophoretic migration of base composition and peptidoglycan dibasic amino acids. J Med Microbiol 1990; 33: 183-188.

43. Lawson PA, Gharbia SE, Shah H, Clark DR. Recognition of Fusobacterium nucleatum subgroup $\mathrm{Fn}-1, \mathrm{Fn}-2$ and $\mathrm{Fn}-3$ by ribosomal RNA gene restriction patterns. FEMS Microbiol Letts 1989; 65: 41-45.

44. Rathore MH, Barton LL, Dunkle LM. The spectrum of fusobacterial infections in children. Pediatr Infect Dis $J$ 1990; 9: 505-508.

45. Romero R, Mazor M, Morrotti $\mathrm{R}$ et al. Infection and labor. VII. Microbial invasion of the amniotic cavity in spontaneous rupture of membranes at term. Am J Obstet Gynecol 1992; 166: 129-133.

46. Chaim W, Mazor M. Intraamniotic infections with fusobacteria. Arch Gynecol Obstet 1992; 251 : 1-7.

47. National Committee for Clinical Laboratory Standards. Approved standard reference agar dilution procedure for antimicrobial susceptibility testing for anaerobic bacteria. NCCLS, Villanova, PA. 1985; 5: 25-38.

48. Johnson CC, Wexler HM, Becker S, Garcia M, Finegold SM. Cell-wall defective variants of Fusobacterium. Antimicrob Agents Chemother 1989; 33: 369-372.

49. Brazier JS, Goldstein EJC, Citron DM, Ostovari MI. Fastidious Anaerobe Agar compared with Wilkins-Chalgren Agar, Brain-Heart Infusion Agar, and Brucella Agar for susceptibility testing of Fusobacterium species. Antimicrob Agents Chemother 1990; 34: 2280-2282.

50. Appelbaum PC, Spangler SK, Jacobs MR. Beta-lactamase production and susceptibilities to amoxycillin, amoxycillinclavulanate, ticarcillin, ticarcillin-clavulanate, cefoxitin, imipenem and metronidazole of 320 non-Bacteroides fragilis Bacteroides isolates and 129 fusobacteria from 28 US centers. Antimicrob Agents Chemother 1990; 34: 1546-1550.

51. Tunér $K$, Lindqvist $L$, Nord $C E$. Characterization of a new $\beta$-lactamase from Fusobacterium nucleatum by substrate profiles and chromatofocusing patterns. $J$ Antimicrob Chemother 1985; 16: 23-30. 